\title{
Close Encounters: Spatial Distances between People and a Robot of Mechanistic Appearance *
}

\author{
Michael L Walters, Kerstin Dautenhahn, Kheng Lee Koay, Christina Kaouri, René te Boekhorst, \\ Chrystopher Nehaniv, Iain Werry, David Lee \\ \{M.L.Walters, K.Dautenhahn\}@herts.ac.uk \\ Adaptive Systems Research Group, School of Computer Science \\ University of Hertfordshire \\ College Lane, Hatfield, Herts, AL10 9AB, UK
}

\begin{abstract}
This paper presents the results from two empirical exploratory studies of human-robot interaction in the context of an initial encounter with a robot of mechanistic appearance. The first study was carried out with groups of children, and the second with single adults. The analysis concentrates on the personal space zones and initial distances between robot and humans, the context of the encounters and the human's perception of the robot as a social being. We discuss the results of these observations and analyses, and also compare the child and adult data. The child groups showed a dominant response to prefer the 'social zone' distance, comparable to distances people adopt when talking to other humans. From the single adult studies a small majority preferred the 'personal zone', reserved for talking to friends. However, significant minorities deviate from this pattern. Implications for future work are discussed.
\end{abstract}

Index Terms - Robot, Human-Robot Interaction, Social Spaces, Distances, Social Robot.

\section{INTRODUCTION}

The field of research into social and personal spaces with regard to robots, designed for use in the home, is a particular area of research within the wider field of Human - Robot Interaction (HRI). Although speech is an incidental part of these interactions, the main emphasis of this research is on the physical, spatial, visual and audible non-verbal social aspects of robots interacting socially with humans. An excellent overview of socially interactive robots (robots designed to interact with humans in a social way) is provided in Fong et al. [1]. As the study of socially interactive robots is relatively new, experimenters in the field often use existing research into human-human social interactions as a starting point. Hall [2] provided the original basis for research into social and personal spaces between humans, and later work in psychology has demonstrated that social spaces substantially reflect and influence social relationships and attitudes of people. Embodied non-verbal interactions, such as approach, touch, and avoidance behaviors, are fundamental to regulating human-human social interactions [3], and this has provided a guide for more recent research into human reactions to robots [4-7]. While the methods used to study human-human interaction may be relevant to this type of study, and the aim of many robot designers is to create robots that will interact socially with humans, it is probable that humans will not react socially to robots in exactly the same way that they react to other humans [8-12]. Previous work has generally assumed that robots are perceived as social beings and that humans will respond to a robot in a similar way, for example, as to a pet, another human, or even as to a child or infant. Evidence exists that humans do respond to certain social characteristics, features or behaviors exhibited by robots [13-15].

The research hypothesis advanced for empirically testing human-robot social space zones was that human-robot interpersonal distances would be comparable to those found for human-human interpersonal distances $[2,3]$. The generally recognized personal space zones between humans are well known and are summarized (for northern Europeans) in Table 1 [16], which summarizes Hall's original distances.

TABLE 1

HUMAN-HUMAN PERSONAL SPACE ZONES

\begin{tabular}{|l|l|l|}
\hline Personal Space Zone & \multicolumn{1}{|c|}{ Range } & \multicolumn{1}{|c|}{ Situation } \\
\hline Close Intimate & 0 to $0.15 \mathrm{~m}$ & $\begin{array}{l}\text { Lover or close friend } \\
\text { touching }\end{array}$ \\
\hline Intimate Zone & $0.15 \mathrm{~m}$ to & Lover or close friend only \\
& $0.45 \mathrm{~m}$ & \\
\hline Personal Zone & $0.45 \mathrm{~m}$ to \\
& $1.2 \mathrm{~m}$ & $\begin{array}{l}\text { Conversation between } \\
\text { friends }\end{array}$ \\
\hline Social Zone & $1.2 \mathrm{~m}$ to & $\begin{array}{l}\text { Conversation to non- } \\
\text { friends }\end{array}$ \\
\hline Public Zone & $3.6 \mathrm{~m}$ & Public speech making \\
\hline
\end{tabular}

We expect that in scenarios designed for direct human-robot interaction, people would assume distances that correspond to the Social or Personal zones (similar to the distances people use when having face-to-face conversations), thus treating the robot as a social being.

\section{THE STUDIES}

Two exploratory studies were carried out using commercially available, human-scaled, PeopleBot ${ }^{\mathrm{TM}}$ robots. The first study took advantage of a larger software evaluation event, run by the FP5 European Project VICTEC [17], by providing 30-minute sessions for 24 groups of 10 children

\footnotetext{
* The work described in this paper was conducted within the EU Integrated Project COGNIRON ("The Cognitive Robot Companion") and was funded by the European Commission Division FP6-IST Future and Emerging Technologies under Contract FP6-002020.
} 
involving interactive games with a PeopleBot ${ }^{\mathrm{TM}}$ robot. The second study involved single human subjects interacting with the PeopleBot ${ }^{\mathrm{TM}}$ robot in simulated living room scenarios. Prior to both studies, initial social space and comfort distance observations and measurements were carried out providing the main focus of this paper.

\section{THE CHILD STUDY}

\section{A. Experimental Setup and Procedure}

The robots used were commercially available PeopleBot robots fitted with a lifting arm, a pink hand, and a small basket which was used to hold small presents (Fig. 1). The arm could be raised or lowered under program control. The experiment was performed in an enclosed area of $6 \mathrm{~m} \times 6 \mathrm{~m}$ which was marked out from the centre with a series of concentric circles at $0.5 \mathrm{~m}$ radii intervals.

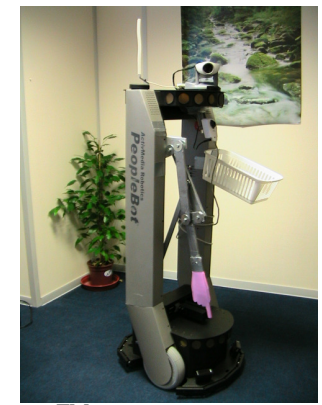

Fig. 1: The PeopleBot ${ }^{\mathrm{TM}}$ robot fitted with arm and hand. This robot was used in the children's study.

The robot was positioned initially at the center of the circles, so an observer was able to use these to estimate the initial distance and relative orientation of members of each group; either directly or from the video recording of the session. The robots were controlled in a semi-autonomous manner, with the Wizard of Oz (WoZ) [18] operators hidden in an adjoining third room along with necessary equipment. The sessions were coordinated by an experimenter and followed the same overall format outlined here:

1) The children entered the room and each child was given a numbered sticker that was attached to their clothing so that the children could be tracked through the experiment.

2) An initial opinion questionnaire was administered before the children saw the robot and also asked for their genders and tracking numbers.

3) The robot was then uncovered and the experimenter let the children move around the robot without giving them any indication of where they should position themselves. Once settled, usually after a period of approximately 1 minute, each child's relative position and orientation towards the robot was recorded on paper record charts (cf. Fig. 2). The initial distances were estimated to the nearest $0.5 \mathrm{~m}$ circle marking on the floor, giving an accuracy of $\pm 0.25 \mathrm{~m}$. Also recorded was whether a teacher was present at the session, along with any other relevant observations.

4) Two interactive games were then played before a final questionnaire was administered. (These latter parts of the session were separate experiments and are not here).
The position and orientation measurements were later checked and verified against the video record after the session. This initial position information was recorded before the children had participated in the games (so before any interaction took place) and before the children had actually seen the robot move. The robot was stationary, though powered up and activated. Therefore, noises from the sonar range sensors and motors were audible throughout the game area.

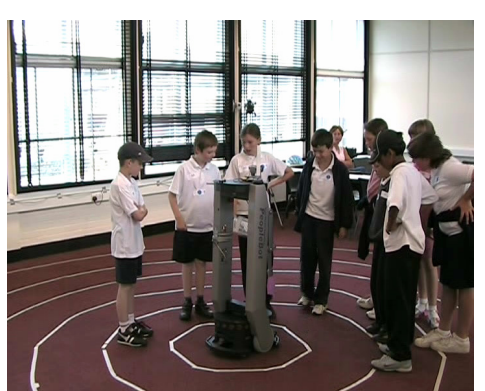

Fig. 2: A group of children take up their positions relative to the robot on their first encounter.

The PeopleBot ${ }^{\mathrm{TM}}$ robot was mechanistic in appearance, so the only visual cues that indicated the front of the robot were:

1) The direction which the robot moved, either forwards or reverse, gave an indication of possible front and rear ends of the robot. This was not apparent until the robot moved, which did not occur at this stage of the test. Therefore, it would not be a factor to consider in this part of the study.

2) The Camera was mounted on top and to the front edge of the robot and pointed forward when the robot was activated but was stationary.

3) The PeopleBots used in the experiment were fitted with a simple arm, on the right hand side. It was in its lowered position at this stage of the experiment. On the left hand side, the robots were fitted with a basket (empty at this stage) to hold presents which would be given during the course of the later game experiment.

\section{B. Results from the Child study}

From the total sample of 196 children, only 131 (71 boys and 60 girls) have been included in the analysis. This was either because some of the children had been told explicitly where to stand initially by a teacher or adult, or were not given an opportunity to take up their initial positions. The initial distance results are summarized below and in Fig. 3.

Initial Distances; All - Mean $=1.73 \mathrm{~m}$, Median $=1.75 \mathrm{~m}$, St. Dev. $=0.73 \mathrm{~m}$

Girls Initial Distances - Mean $=1.74 \mathrm{~m}$, Median $=1.75 \mathrm{~m}$, St. Dev. $=0.61 \mathrm{~m}$

Boys Initial Distances - Mean $=1.72 \mathrm{~m}$, Median $=1.25 \mathrm{~m}$, St. Dev. $=0.73 \mathrm{~m}$

The children initially tended to place themselves at an overall mean distance of $1.75 \mathrm{~m}(\mathrm{St} \mathrm{Dev}=0.73)$ which is consistent with the social distance which would be used by humans to communicate with non-friends, and ranges from $1.2 \mathrm{~m}$ to $3.6 \mathrm{~m}$ (social zone, cf. Table 1 ). 


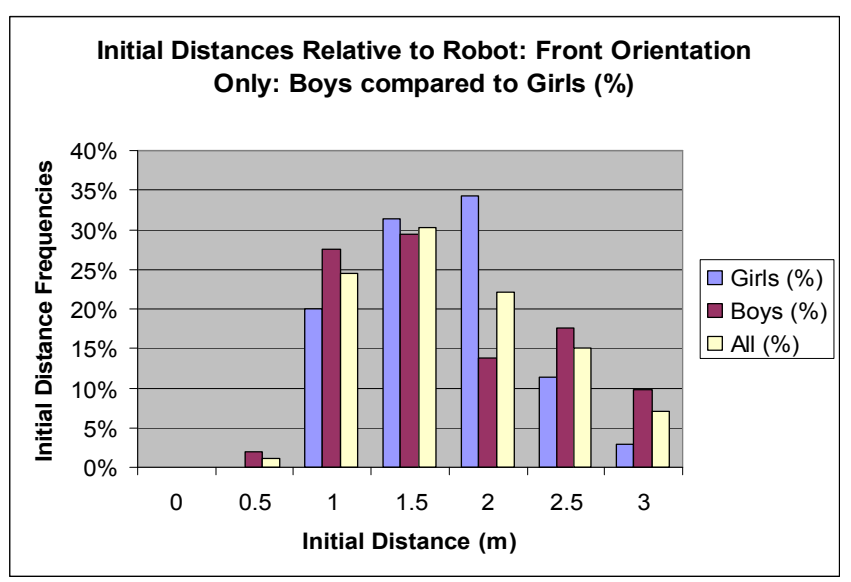

Fig 3: Frequencies of initial distances relative to robot: Front orientation only, for boys, girls and all children

The implication is that most of the children might have related to the robot as a social entity, even though the PeopleBots used for the study only had one arm (which was the only explicit anthropomorphic feature). The robot's onboard video camera may also have acted as a focus of the children's attention, the children may have been eager to interact due to the play context or because of the detailed preparation necessary for the event to take place (a school excursion), they may have been primed to expect an interaction with the robot to take place.

The initial orientation of each child was estimated by which quarter each child was initially positioned in relative to the robot, and recorded as front, right, left or back. The results are summarized in Table 2. The initial distance and orientation results presented here suggest that there is a strong tendency for a majority of just over half of the children (53\%) to position themselves to the front of the robot initially. There was also an indication that proportionally more boys than girls (59\% to $47 \%$ ) positioned themselves at the front of the robot. However, although the mean distance of the boys from the robot $(1.72 \mathrm{~m}$, St Dev $=0.73)$ is similar to the girls mean distance $(1.74 \mathrm{~m}$, St Dev $=0.61)$, it can be seem from the standard deviation values and from the chart (Fig. 3) that the boys actually tended to place themselves initially either relatively closer to, or further away from, the robot than the girls who tended to exhibit a more compact normal distance frequency distribution.

From the number of children who positioned themselves at the front of the robot $(53 \%)$, one might infer that the camera or the pointer (or both together) are powerful attractors of the children's initial attention, even though the camera, arm and robot were stationary. There may also be a weaker indication that the stationary arm pointer possibly had some effect in causing some children to prefer positions on the robot's right side $(21 \%)$ as opposed to left side $(12 \%)$ or behind the robot $(12 \%)$. However, the entrance to the game area was to the right of the robot so this may possibly have affected this observed right-left preference. Further experiments should control for this and also for the initial orientation of the robot.
TABLE 2

CHILDREN'S INITIAL ORIENTATION MEASUREMENTS

\begin{tabular}{ll|}
$\begin{array}{l}\text { Children's Initial Orientations Relative } \\
\text { to PeopleBot Robot. }\end{array}$ \\
\hline \begin{tabular}{ll} 
Children in front of robot & $70(53 \%)$ \\
Children to right of robot & $27(21 \%)$ \\
Children to left of robot & $16(12 \%)$ \\
Children behind robot & $16(12 \%)$ \\
\hline
\end{tabular} \\
\hline
\end{tabular}

\section{THE AdULT STUDY}

\section{A. Experimental Setup and Procedure}

This study was an exploratory investigation and involved twenty-eight single subject sessions with individual adults interacting with a single robot in simulated living room scenarios. These experiments applied a human-centered perspective; which is concerned with how people react to and interpret a robot's appearance and/or behavior, regardless of the cognitive processes that might happen inside the robot (robot-centered perspective). A large conference room was converted and furnished to provide as homely a environment as possible. Adjacent was an enclosed section where the WoZ robot operators and equipment were housed.

The subject sample set consisted of 28 adult volunteers [male: $\mathrm{N}: 14(50 \%)$ and female: $\mathrm{N}: 14(50 \%)]$ recruited from the University. A small proportion (7\%) was under 25 years of age, but no one younger than 18 took part. Approximately $43 \%$ were 26-35 years old, $29 \%$ 36-45 years old, $11 \%$ 46-55 years old and $11 \%$ were over 56 years of age. $39 \%$ of the participants were students, $43 \%$ academic or faculty staff (e.g. lecturers, professors) and $18 \%$ were researchers in an academic institution. Approximately 50\% came from a robotics or technology-related department (e.g. computer science, electronics and engineering), and 50\% came from a non-technology related department, such as psychology, law or business. All subjects completed consent forms and were not paid for participation, but at the end of the trial they were given a book as a present.

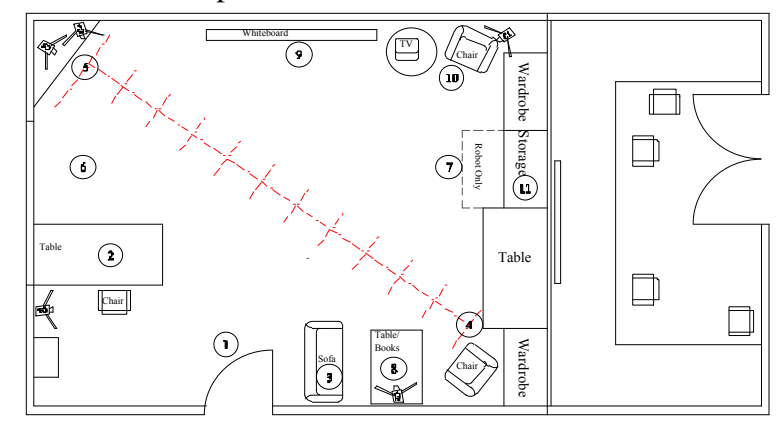

Fig. 4: Plan view of simulated living room layout. Comfort distance tests carried were out along the marked diagonal line.

The initial distance measurements were performed before a separate experimental session involving human-robot interactions in task based scenarios. Scale marks were made 
at $0.5 \mathrm{~m}$ intervals along the diagonal of the room (Figs. 4 and 5 ) and the human-robot comfort and approach distances were estimated from the video records, rather than making intrusive measurements or notes during the sessions. The robot's arm was adapted so that it could pick up and carry small palettes which contained items to be brought to the human subject later on in the task scenarios (Fig. 6) (Note; The hand was not as anthropomorphic in appearance as that used for the child study). Each experiment session followed the same format:

1) Entry to room and introduction of robot

2) Co-habituation and initial questionnaires. While the subject was completing the questionnaires, the robot wandered randomly around the test area. Unlike the first study the subject was allowed to acclimatize to the robot for five to ten minutes prior to the distance tests.

3) Comfort and social distance tests.

4) Various other HRI task scenarios and questionnaires. (These latter parts were carried out for separate HRI investigations and are therefore not considered in this paper).
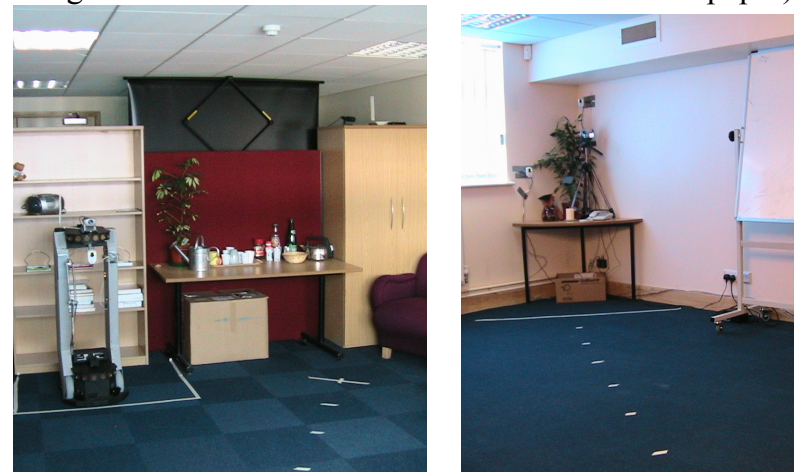

Fig. 5: Views of simulated living room showing robot and the $0.5 \mathrm{~m}$ scale marked diagonally on the floor

The experiments were supervised by an experimenter who introduced and explained the tests to be carried out to the subject. Otherwise, she interfered as little as possible with the actual experiment. For measuring the human subject's comfortable distance when approaching the robot, the robot was driven to point 5 (next to the corner table) and turned to face along the distance scale towards point 4 (Fig. 4). The subject was told to start at point 4 and to move towards the robot until he or she felt that they were at a comfortable distance away from the robot. Next, they were told to move as close to the robot as they physically could, then to move away again to a comfortable distance. They were then told to repeat these steps once again as a consistency check. The comfortable approach, closest physical and comfortable withdrawal distances were measured for each of the two tests to the nearest $0.25 \mathrm{~m}$ (accuracy $\pm 0.125 \mathrm{~m}$ ) by later close observation of the video records. The next part of the comfort distance tests was to measure the subject's comfort distance with the robot moving from point 5 towards the subject. The subject was told to stand at point 4 , and the robot moved directly towards him or her. The subject was told to say, "Stop", when the robot was as close as the subject desired. The distance of the robot when the subject said, "stop" was estimated later, and recorded, from close observation of the video records.

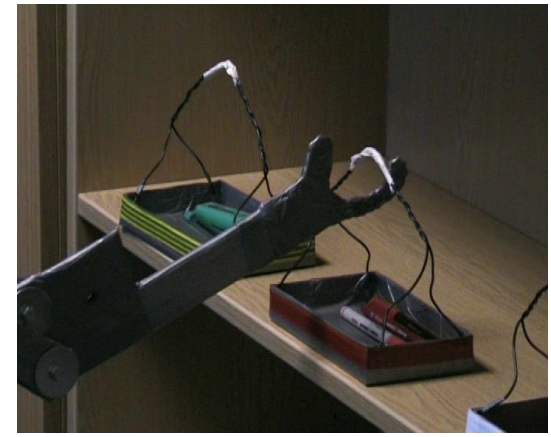

Fig 6: Detail showing the robot's arm and hand used in the study with adult subjects.

\section{B. Results from the Adult Study}

The means of the four robot comfortable approach distance results obtained was calculated for each subject and the frequency histogram was plotted, with the ranges set at $0.25 \mathrm{~m}$ intervals. The results are presented in the chart in fig. 7 . Approximately $40 \%$ of subjects approached the robot to a distance of $0.5 \mathrm{~m}$ or less. When the robot approached a human, the anti-collision safety system prevented it moving closer than $0.5 \mathrm{~m}$. Due to safety concerns this system must be kept operational.

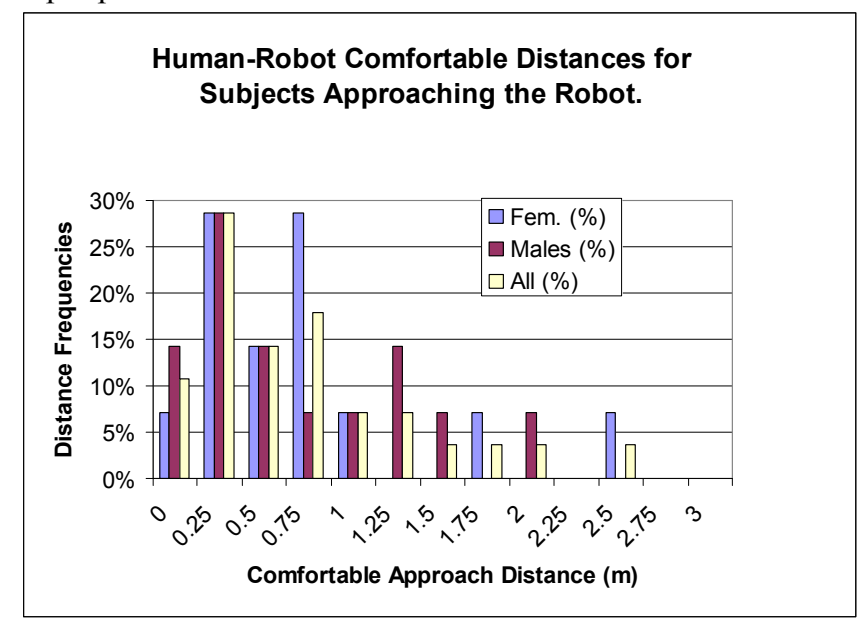

Fig. 7: Comfortable approach distance frequencies for subjects approaching the robot.

It can be seen that approximately $40 \%$ of the subjects also allowed the robot to approach right up to this $0.5 \mathrm{~m}$ limit. That they did not stop the robot from physically approaching so closely to them indicates that the robot did not make them feel threatened or uncomfortable. When asked later if they felt uncomfortable while standing in front of the robot most subjects $(82 \%)$ indicated that they were not uncomfortable. Also, as less than $20 \%$ indicated that they wanted a robot for a friend or companion, these close approach distances did not express the subjects' wish to be intimate with the robot. That many of the subjects approached the robot closely, and tolerated a relatively close approach implies that they might not see the robot as a social entity in the same way that they 
would perceive another human. If another, unfamiliar human (a stranger) was to approach to the same close distances; most humans would feel distinctly uncomfortable and threatened. Interestingly, there were a small number of subjects (approximately 10\%) who were uncomfortable in letting the robot approach closer than the far end of the social zone $(>1.2 \mathrm{~m}$ and $<3.6 \mathrm{~m})$, which is usually reserved for conversations between humans who are strangers to each other.

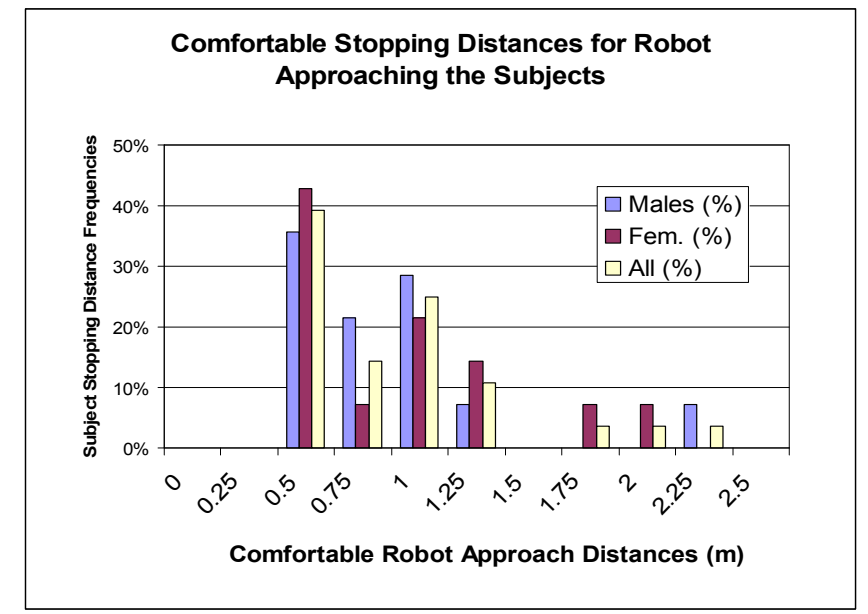

Fig. 8: Comfortable approach distance frequencies for the robot approaching the Subjects.

\section{COMPARISON AND DISCUSSION OF RESULTS FROM BOTH STUDIES}

While the experimental setups of both studies were very different, comparisons between the comfort zones measured in both studies can highlight results which generalize across the two different experimental setups. In both studies, for the children and adult subjects, a majority took up an initial position relative to the robot which was consistent with treating the robot as a social being with respect to accepted human-human social space zones. In both studies, the floor was marked with scale marks in order to aid the distance measurements and this may have influenced the distance results obtained. A major difference between the two social distance studies was that the children were interacting with the robot in groups, whereas the adults were interacting individually with the robot. It is very likely that the children took cues from, and were interacting with each other as well as the robot; cf. a discussion of social facilitation effects in Woods et al. [19]. Almost all the children generally took up a mean distance which would, amongst humans, be reserved for talking or interacting with strangers or other non-friends. However, most adults took up a distance which in a humanhuman context would be used for talking with friends. Generally, these results support our initial research hypothesis, namely that distances used in direct human-human social interaction can apply to robots. In both cases, this could however simply be a convenient distance for viewing the robot, so more tests are required to confirm the reasons for these observations. A small proportion of each group took up an initial distance as far from the robot as the limited space allowed.

Interestingly, amongst the adults, there was a sizable minority (approximately 40\%) who took up an initial position relative to the robot which was so close that it would be classified as that reserved for intimate lovers or friends. This probably means that those subjects did not see or treat the robot as a social being. Pamela Hinds and colleagues [20] have studied the effect of robot appearance on humans carrying out a joint task with a robot. They found that humans treat mechanistic looking robots in a subservient way (i.e. less socially interactive) compared to more humanoid looking robots. Also expectations are lower as regards abilities and reliability for mechanistic looking robots.

The PeopleBot ${ }^{\mathrm{TM}}$ robots used in the studies were fitted with a moving articulated arm. However, they are still very mechanistic in their appearance, so it is probable that many subjects in the adult experiment simply did not recognize the robot as anything more socially interesting than any other household object or machine (such as a refrigerator or television). Amongst the children, only a very few went so close to the robot initially. Results indicate that they possibly saw the robot as a social entity. This may reflect their different expectations, lesser discrimination and self-consciousness in interacting with the robot in a play context.

For both child and adult studies the social distance experiments were performed before any other interactions had taken place. With more opportunity for habituation, the perception of the subjects may have changed over the course of the experiments. It would be useful to perform distance experiments both before and after exposure to robot scenarios to see how subjects' perceptions change with both short and longer term exposure to robots. There is a need, therefore, to perform long-term studies (over periods of longer than one hour) and repeated exposure of the subjects to the robot over longer periods of time.

The adult study did not consider the initial orientation of the subjects to the robot, due to lack of space in the experimental room, but the children's study did gain results that indicated that the only two possible anthropomorphic features which distinguished the front and back of the robot, the hand/arm and the camera, did probably exert an effect on where the children chose to orientate themselves when initially encountering the robot. There are also some indications that the arm and hand may also exert a right hand bias to the children's initial orientations, though this needs further study to confirm as the entry to the game arena was also to the right of where the robot was positioned initially.

\section{CONCLUSIONS}

We cannot claim that the results gained as part of these two studies, using PeopleBots, can be generalized to any other type of robot or to any other context/scenario. The PeopleBots are mechanistic in appearance. These results could only possibly be extrapolated to include similar other robots. 
Interestingly, substantial individual differences have been found in how people behaved towards the PeopleBot robot, although most of the human subjects participating in the studies seemed to be receptive to treating the robot as a (limited) social entity after only a short period. It seems that children in particular are more overall more accepting and approving of robots than the adult subjects studied. The social distance results so far have indicated that a substantial minority of adults ( $40 \%$ in our adult sample) do not seem to perceive the PeopleBot ${ }^{\mathrm{TM}}$ robot as a social being at first encounter. There was a small but significant proportion of both children and adults, in the two studies documented here, who seem to be uncomfortable in the presence of the PeopleBot ${ }^{\mathrm{TM}}$ robot.

There is a need for long term trials with a variety of types of robots in order to determine which social features are most effective at making human robot interaction robot more efficient and useful to humans. The CERO robot assistant study [21], the Robovie peer tutor robot trials with children [22], and trials involving children with autism interacting with a humanoid robot [23] are examples of the few published works which describe studies involving long term periods of humans interacting with robots. Different robot social models, perhaps with very different initial personalities, may be more acceptable to different users (e.g. a discreet servant or even a silent servant, with no obvious initiative or autonomy). Our results suggest that it probably cannot be assumed that people automatically treat robots socially, apart from simple elements of anthropomorphism cf. Reeves and Nass [24]. A user friendly robot should automatically refine and adapt its social model (personality) over a longer period of time, depending on information about and feedback from users and the robots own autonomous learning system. For example, adjustments of social distances according to a user's personality traits (as proposed in [25]) is a promising direction towards a true robot companion that needs to be individualized, personalized and adapt itself to the user [26].

\section{ACKNOWLEDGEMENTS}

Thanks go to Ben Robins, Alexander Klyubin, Lars Olssen and Aris Alissandrakis for their help in carrying out the trials.

\section{REFERENCES}

[1] T. Fong, I. Nourbakhsh, and K. Dautenhahn, (2003). A survey of socially interactive robots. Robotics and Autonomous Systems, vol. 42, pp. 143166, 2003.

[2] E.T. Hall, (1966). The Hidden Dimension: Man's Use of Space in Public and Private. The Bodley Head Ltd, London, UK. 1966

[3] E. T. Hall, (1968). Proxemics. Current Anthropology 9(2-3): 83-108. 1968

[4] J. Goetz and S. Kiesler, (2002). Cooperation with a Robotic Assistant Proc. CHI'02 Conference on Human Factors in Computing Systems, New York, USA, 2002.

[5] A. Paiva, J. Dias, D. Sobral. R Aylett, P Sobreperez, S Woods et al, (2004). Caring for Agents and Agents that Care: Building Empathic Relations with Synthetic Agents. Third International Joint Conference on Autonomous Agents and Multiagent Systems (AAMAS'04), pp. 194201. July $19-23,2004$
[6] M. Scopelliti, M. V. Giuliani, A. M. D'Amico, and F. Fornara, (2004). "If I had a robot at home.... Peoples' representation of domestic robot". in Designing a more inclusive world, S. Keates, J. Clarkson, P. Langdon, and P. Robinson, Eds. Cambridge, UK: Springer, 2004, pp. 257-266.

[7] S. Woods, K. Dautenhahn, J. Schulz, (2004). The Design Space of Robots: Investigating Children's Views. Proc. IEEE RO-MAN Conference, 13th IEEE Int. Workshop on Robot and Human Interaction Communication. Kurashiki, Japan. Sept 2004.

[8] D. A. Norman, (1994). How might people interact with agents, Communications of the ACM, vol. 37, pp. 68-71, 1994.

[9] D. C. Dryer, (1999). Getting personal with computers: How to design personalities for agents., Applied Artificial Intelligence, vol. 13, pp. 273295, 1999.

[10]Z. Khan, (1998). Attitude towards intelligent service robots. NADA KTH, Stockholm 1998

[11]K. Dautenhahn, (2002): Design Spaces and Niche Spaces of Believable Social Robots. Proc. 2002 IEEE Int. Workshop on Robot and Human Interactive Communication ROMAN 2002, 25-27 September, Berlin, Germany, pp. 192-197, IEEE Press.

[12]K. Dautenhahn, B. Ogden, T. Quick (2002). From Embodied to Socially Embedded Agents - Implications for Interaction-Aware Robots, Cognitive Systems Research 3(3), pp. 397-428)

[13]C. L. Breazeal, (2002). Designing sociable robots. Massachusetts: The MIT Press, 2002.

[14]B. Friedman, P. H. Kahn (Jr.), and J. Hagman, (2003). "Hardware companions? What online AIBO discussion forums reveal about the human-robotic relationship," Digital Sociability, vol. 5, pp. 273-280, 2003

[15] Sony, (2004). "Sony Entertainment Robot Europe http://www.aiboeurope.com/".

[16]D Lambert, (2004). Body Language. HarperCollins.

[17]VICTEC, (2003). VICTEC Project website available at http://www.victec.org, 2003.

[18]A. Green, H. Hüttenrauch, K. Severinson Eklundh (2004). Applying the Wizard of $\mathrm{Oz}$ Framework to Cooperative Service discovery and Configuration. Proc. IEEE Ro-man 2004, 13th IEEE International Workshop on Robot and Human Interactive Communication, Okayama, Japan, IEEE Press.

[19]S Woods, K Dautenhahn, C Kaouri, (2005) Is Someone Watching Me? Consideration of Social Facilitation Effects in Human-Robot Interaction Experiments. Proc. IEEE CIRA 2005.

[20]P Hinds, T Roberts, H Jones, (2004). Whose Job Is It Anyway? A Study of Human-Robot Interaction in a Collaborative Task. Human-Computer Interaction, 2004 Vol. 19 pp151-181.

[21]K Severinson-Eklundh, Anders Green, Helge Hüttenrauch, (2003). Social and Collaborative Aspects of Interaction with a Service Robot. Robotics and Autonomous Systems 42 (2003) pp. 223-234.

[22]T Kanda, T Hirano, D Eaton, (2004). "Interactive Robots as Social Partners and Peer Tutors for Children: A Field Trial". Human-Computer Interaction, 2004, Vol. 19, pp. 61-84.B

[23]Robins, K Dautenhahn, R te Boekhorst, A Billard, (2004) "Effects of repeated exposure to a humanoid robot on children with autism". In S. Keates, J. Clarkson, P. Langdon and P. Robinson (Eds.) Designing a More Inclusive World, Springer Verlag, London, pp. 225-236.

[24]B Reeves, C Nass, (1996). The Media Equation: How people treat computers, television and new media like real people and places. Cambridge University Press 1998. ISBN 157586052x

[25]M L Walters, K Dautenhahn, R te Boekhorst, K L Koay, C Kaouri, S Woods, C L Nehaniv, D Lee, I Werry, (2005) The Influence of subjects' Personality Traits on Personal Spatial Zones in a Human-Robot Interaction Experiment. Proc. IEEE Ro-man 2005, $14^{\text {th }}$ Annual Workshop on Robot and Human Interactive Communication, 13-15 Aug 2005. Nashville, Tennessee, USA.. IEEE Press, pp. 347-352.

[26]K Dautenhahn, (2004). Robots We like to Live With?! - A Developmental Perspective on a Personalized Life-Long Robot Companion. Proc. IEEE Ro-Man 2004, 13th Annual Workshop on Robot and Human Interactive Communication, September 20-22, Kurashiki, Okayama, Japan. IEEE Press, pp. 17-22. 